\title{
Capuchin monkeys can make and use stone tools
}

\author{
Edward A. Wasserman ${ }^{1} \cdot$ Roger K. R. Thompson ${ }^{2}$
}

Published online: 11 January 2017

(C) Psychonomic Society, Inc. 2017

\begin{abstract}
Summary Scientists hoping to elucidate the origin of human stone tool manufacture and use have looked to extant primate species for possible clues. Although some skepticism has been raised, there is clear evidence that today's capuchin monkeys can make and use stone tools.
\end{abstract}

Keywords Tool use $\cdot$ Contingency judgment $\cdot$ Human learning

Proffitt et al. (2016) recently reported in Nature that wild capuchin monkeys unintentionally produce sharp stone flakes, but they do not purposefully use these flakes for cutting. In an associated opinion piece, the Editors of Nature downplayed any connection between these findings and the development of human stone tool production and use. We disagree with their contention and instead propose that the inadvertently produced stone flakes of both early hominids and today's capuchin monkeys might plausibly set the stage for their later instrumental deployment. Indeed, we cite empirical evidence that, at least in captivity, capuchin monkeys can make and use stone tools for cutting.

Specifically, Proffitt et al. (2016) reported that wild bearded capuchin monkeys (Sapajus libidinosus) in Brazil "deliberately break stones unintentionally producing . . . sharp-edged flakes and cores that have the characteristics and morphology

Edward A. Wasserman

ed-wasserman@uiowa.edu

1 Department of Psychological and Brain Sciences, The University of Iowa, 301 East Jefferson Street, Iowa City, IA 52242, USA

2 Franklin \& Marshall College, Lancaster, PA, USA of intentionally produced hominin tools chipped from larger rock cores" (p. 85, italics added). Stone breaking by capuchins is not remarkable in and of itself. The roots of the often observed functional use of stones as hammer tools by both wild and captive capuchin monkeys likely lies in the natural tendency of individuals as young as 6 months of age to pound objects directly on a substrate. What is noteworthy in the Proffitt et al. report is that any instrumental function of these deliberatively produced stone flakes - other than their possibly serving as a source of trace nutrients when they are licked-remains mysterious. The monkeys "were not observed using the sharp edges of fractured tools to cut or scrape other objects" (p. 85).

Nevertheless, Proffitt et al. (2016) offered an interesting speculation: "If encountered in a hominin archaeological context, this material would be identified as artefactual, potentially interpreted as the result of intentional stone fracture and controlled flake production, and probably attributed to functional needs requiring the use of sharp edges" (p. 87). If nothing else, then the monkeys' production of stone flakes raises the strong possibility of anthropologists' misinterpreting archeological evidence of hominin tool manufacture and use. Of course, we can never be entirely certain of our progenitors' instrumental use of similar stone shards, although there are widely accepted methods for reading the archeological evidence (Schick \& Toth, 1993).

Despite having chosen to publish this intriguing empirical report, the editors of Nature dismissed any evolutionary connection between the present monkey findings and the development of human stone tool production and use. In their associated editorial, they concluded:

In the end, the activity of banging rocks together should be seen as precisely that, and not as the first, proleptic step towards the stars. The ape-man at the start of 2001: 
A Space Odyssey that throws a bone in the air that becomes a space station was, after all, a modern human in a gorilla suit. (Nature Editorial, 2016, p. 290)

Perhaps the editors protested too much. Is it really so farfetched to imagine that early hominids, like today's capuchins, accidentally knapped stone flakes when, much like today's monkeys, they were cracking nuts to eat or pulverizing stones to release powdered quartz or lichens to lick? Such inadvertently produced stone flakes might well have set the stage for the innovative deployment of those flakes to the clearly instrumental tasks of cutting and scraping.

One way that such instrumental deployment might have developed is by the stone-wielding primate accidentally being wounded during stone striking: "since a shattering stone hammer can cut the hand, a hominid could have been duly impressed with the sharpness of fragments" (Schick \& Toth, 1993, p. 145). Beyond experiencing the painful lesson inflicted by the sharp stone, the hominid would have "to explore how this new invention could be applied to other possible tasks" (Schick \& Toth, 1993, p. 145). This or some other trial-and-error process need only to have yielded a single pioneering hominid whose tool-making success was passed along to others in much the same way that human innovations are socially and culturally transmitted to conspecifics (Wasserman, 2012).

This discussion returns us to the report at issue: namely, the finding that today's wild capuchin monkeys have yet to be seen making stone flakes that they use to perform some clearly identified instrumental task. The present failure for researchers to identify such instrumental behavior in no way proves that capuchins altogether lack the cognitive capability for doing so.

In point of fact, one pioneering capuchin stone toolmaker and user has been observed in captivity. Morris was one of three tufted capuchin monkeys (Cebus sajapus) that Westergaard and Suomi (1994) observed using intact stones as tools to strike or hammer through a sheet of clear acetate covering a container in which sweet syrup was available. However, of those three animals, only Morris also modified stones that were initially too large to be functional by striking quartzite rocks against a hard container or other stones, thereby reducing the size of the stone cores and producing sharp flakes which he then used to cut through the clear acetate cover. Importantly, Morris did so spontaneously, without explicit training, demonstration, or food or water deprivation.

Morris's innovative manufacture and use of the sharp stone flakes can be seen to provide unique behavioral evidence that the ability to perceive the functional affordances of the stone flakes as cutting tools is well within the ken of capuchin monkeys. Westergaard and Soumi (1994) thus interpreted Morris's behavior as providing strong supportive evidence for "crossspecies continuity in the tool-using and tool-making abilities of primates and [for stone-tool technology having possibly] evolved in the hominid lineage earlier than has been confirmed by the existing archeological record" (p. 399).

Although they did not cite the important work of Westergaard and Soumi (1994) in their paper, Proffitt et al. (2016) were aware of it; they chose not to discuss it within the narrow confines of their field report of wild capuchin behavior (M. Haslam, personal communication, December 16, 2016). For the broader questions concerning the evolution of tool construction and use, however, we believe that the research of both teams suggests that today's nonhuman primates and their progenitors may have the requisite cognitive capacity for stone tool manufacture and use. Just what prompts that critical step to be taken remains unknown, although adventitious reinforcement may certainly play a key part. Accidental flaking may thus represent a vital "stepping stone" to instrumental tool manufacture and use.

\section{References}

Nature Editorial. (2016). Sharp practice. Nature, 538, 290.

Proffitt, T., Luncz, L. V., Falótico, T., Ottoni, E. B., de la Torre, I., \& Haslam, M. (2016). Wild monkeys flake stone tools. Nature, 539, 85-88.

Schick, K. D., \& Toth, N. (1993). Making silent stones speak: Human evolution and the dawn of technology. New York: Simon \& Schuster.

Wasserman, E. A. (2012). Species, tepees, scotties, and jockeys: Selected by consequences. Journal of the Experimental Analysis of Behavior, 9. 213-226.

Westergaard, G. C., \& Suomi, S. J. (1994). A simple stone-tool technology in monkeys. Journal of Human Evolution, 27, 399-404. 